\title{
GMR
}

\section{HPV genotyping and p16 expression in Xingu Indigenous Park, Brazil}

\author{
V.G. Freitas ${ }^{1}$, G.R. Focchi ${ }^{2}$, E.R. Pereira ${ }^{3}$, J.E. Levi ${ }^{4}$, N.M.G. Speck ${ }^{1}$ and \\ J.C. Ribalta ${ }^{1}$
}

'Núcleo de Prevenção de Doenças Ginecológicas, Departamento de Ginecologia, Universidade Federal de São Paulo, São Paulo, SP, Brasil

${ }^{2}$ Departamento de Patologia, Escola Paulista de Medicina, Universidade Federal de São Paulo, São Paulo, SP, Brasil

${ }^{3}$ Departamento de Medicina Preventiva, Escola Paulista de Medicina, Universidade Federal de São Paulo, São Paulo, SP, Brasil

${ }^{4}$ Instituto de Medicina Tropical da Universidade de São Paulo, São Paulo, SP, Brasil

Corresponding author: V.G. Freitas

E-mail: valgfreitas@yahoo.com.br

Genet. Mol. Res. 15 (3): gmr.15036840

Received January 4, 2016

Accepted May 24, 2016

Published September 16, 2016

DOI http://dx.doi.org/10.4238/gmr.15036840

Copyright (C 2016 The Authors. This is an open-access article distributed under the terms of the Creative Commons Attribution ShareAlike (CC BY-SA) 4.0 License.

ABSTRACT. The association between high-risk human papillomavirus (HPV) genotypes and p16 expression in indigenous women from the Xingu Indigenous Park, Brazil, was unknown. This study evaluated p16 expression in women with a histological diagnosis of cervical intraepithelial neoplasia (CIN) 3 or higher and correlated this expression with HPV genotypes to determine possible discrepancies in the expression of this marker. We evaluated 37 previously collected samples with different HPV genotypes and high-grade lesions diagnosed based on cytology, histology, and colposcopy. Immunohistochemical analysis was performed using paraffin-embedded tissue sections and 
the CINtec ${ }^{\circledR}$ Histology Kit. p16 protein expression was investigated by immunostaining with an anti-p16 antibody. HPV genotyping was performed by reverse hybridization. The age of the study population ranged from $22-75$ years $(43.81 \pm 15.89$ years) and parity ranged from $1-11(5.92 \pm 2.58)$. Thirteen different HPV genotypes were found using the INNO-LiPA kit. Single and multiple infections by HPV were found with prevalence of single infections $(P=0.029)$. Comparison between HPV genotype and simple or multiple infections was highly significant; it was observed more HPV 52 followed by HPV 16 in single infections ( $\mathrm{P}$ $<0.001)$. p16 expression was predominantly diffuse, which was observed in $91.7 \%$ of lesions, whereas $8.3 \%$ were focal $(\mathrm{P}<0.001)$. HPV 52, HPV 16 and 31 were the most prevalent HPV types in high-grade CIN in these indigenous women. Diffuse p16 expression in high-grade CIN was not influenced by the viral genotype; however, more studies are necessary to further our understanding of this restricted group.

Key words: 16 protein; p16 expression; Human papillomavirus; Indigenous; Xingu; Genotype

\section{INTRODUCTION}

Xingu Indigenous Park (PIX, acronym in Portuguese) is a $26,400-\mathrm{km}^{2}$ region located in Mato Grosso, Brazil. Recent data from Fundação Nacional de Saúde - Mato Grosso (FUNASA/MT) indicated that there are approximately 5500 PIX inhabitants of the following sixteen ethnic groups: Aweti, Ikpeng, Kayabi, Kalapalo, Kamayurá, Kisêdjê or Suiá, Kuikuro, Matipu, Mehinako, Nahukua, Naruvotu, Waujá, Tapayuna, Trumai, Yudjá or Juruna, and Yawalapti. Compared to other native Brazilians, this indigenous population has a peculiar relationship with the non-indigenous society. While outside contacts have spread diseases among them, currently the indigenous people from Xingu are relatively isolated with minimal non-indigenous influence (Kahn et al., 2011).

Cancer has only recently been regarded as an important health issue for Indigenous people (Cunningham et al., 2008). Human papillomavirus (HPV) infection is the known etiologic agent of cervical cancer and precancerous lesions (Zhang et al., 2015). The prevalence of HPV infection in Latin American indigenous women is higher than in the rest of female population (Pereira et al., 2015) and HPV-associated diseases are prominent in indigenous women (Tonon et al., 2004). Sexually transmitted infections (STIs), including those by HPV, are highly prevalent and may cause immense personal, familial, and societal damage (Gracey and King, 2009). The increase of cervical cancer (CC) deaths among indigenous peoples has changed indigenous health policies focusing on the tracking and treatment of precancerous lesions. In 2005, as a result of a partnership between FUNASA and Universidade Federal de São Paulo (UNIFESP), the Xingu Project was created and allowed important changes in preventive screening and treatment for the natives of PIX (Speck et al., 2009). However, few epidemiological studies have looked into this restricted population.

Between years 2005 and 2011, cervical cancer screening was performed in female PIX population, with a total of 2903 cervico-vaginal smears (cytopathological smear coverage about 95\%), 567 colposcopies and 272 cervical biopsies executed in this period.

Genetics and Molecular Research 15 (3): gmr.15036840 
High-risk HPV (HR-HPV) genotypes are associated with CC and other invasive tumors as well as the development of cervical intraepithelial neoplasia (CIN) (Hamid et al., 2009). HPV DNA has been detected in approximately $99 \%$ of invasive CC and is often present in condylomatas and high-grade cervical dysplasias (CIN2/3) (Bell et al., 2007). It is known that are a substantial geographical variation in the HPV genotype distribution but the majority of CC in all world regions is HPV 16 and/or HPV 18 (HPV 16/18)-related (Li et al., 2011). The prevalence of HPV type-specific in each country is mandatory for providing baseline information to predict how vaccination and HPV-based screening will influence cervical cancer prevention (Kietpeerakool at al., 2015). Nowadays, there are several methods for HPV genotyping and the selection of the appropriate one depends on the intended use such as clinical studies, epidemiology and vaccine evaluation (Torres et al., 2012).

HR-HPV oncoproteins E6 and E7 have transforming properties and play an important role in viral replication (Hamid et al., 2009). E6 blocks apoptosis through an interaction with the cellular tumor suppressor protein $\mathrm{p} 53$, whereas E7 binds to members of the retinoblastoma $(\mathrm{Rb})$ tumor suppressor family to facilitate cell cycle progression (Schiffman et al., 2007; Hamid et al., 2009). E7-mediated inactivation of the Rb pathway results in marked overexpression of p16; a gene expressed by the host cell in response to the expression of viral oncogenes but not expressed in normal non-transformed cells. In addition, overexpression of p16 serves as an indirect marker of activated HR-HPV oncogene activity in cervical epithelia (Klaes et al., 2002). The p16 overexpression has been found in the vast majority of CIN2 and CIN3 lesions (Bergeron et al., 2010) and has been widely used as a surrogate biomaker in facilitating accurate diagnosis of CIN2 and CIN3 on tissue sections (Darragh et al., 2013).

Therefore, the aim of the present study was to evaluate the genotypes of HPV infections and p16 expression in a female indigenous population from PIX with histological diagnoses of CIN3 or higher.

\section{MATERIAL AND METHODS}

\section{Study population}

This retrospective observational study was conducted in the Gynecological Disease Prevention Nucleus of the Gynecology Department in collaboration with the Pathology Department and Environmental Department Unit of Preventive Medicine from UNIFESP/EPM.

The Research Ethics Committee of the UNIFESP/EPM and the National Research Ethics Committee under protocol Nos. (CEP) 0549/08 and (CONEP) 14950, respectively, approved the study, and written informed consent was obtained from all participants.

The samples and data from each patient were collected previously. This research included 37 cervical samples from indigenous women from PIX with an age range of 22-75 years. All patients were immunocompetent without any record of medication use, and STD tests were negative. Patients with diagnoses of CIN3 or higher were subjected to excisional surgery treatment, as loop excision of the transformation zone, loop electrosurgical excision procedure, cold knife conization, or hysterectomy, which were performed in 2005-2012. Patients with previous hysterectomy, glandular lesions, or pregnancy were not included in the study.

Genetics and Molecular Research 15 (3): gmr.15036840 


\section{Immunohistochemical analysis}

Formalin-fixed paraffin-embedded (FFPE) tumor tissue blocks was cut into $3-\mu \mathrm{m}$-thick sections by using a sterile blade, and then deparaffinization was performed with a xylene bath at $25^{\circ} \mathrm{C}$ three times for $5 \mathrm{~min}$, followed by $100 \%$ ethanol soak at $25^{\circ} \mathrm{C}$ three times for $1 \mathrm{~min}$. The CINtec ${ }^{\circledR}$ Histology Kit (Roche MTM Laboratories AG, Heidelberg, Germany) was then used for the histological sections, which were washed with water for $5 \mathrm{~min}$, and incubated with Epitope Retrieval Solution 10X (100 mM Tris buffer, pH 9, containing $10 \mathrm{mM}$ EDTA and 15 $\mathrm{mM}$ sodium azide) at $97^{\circ} \mathrm{C}$ for $10 \mathrm{~min}$. Treatment with $3 \%$ hydrogen peroxide in water for $5 \mathrm{~min}$, followed by treatment with wash buffer for 5 min was applied to the sections for endogenous peroxidase blocking. The dilution of antibody was based on manufacturer instructions. Sections were then stained with an anti-p16 antibody (Clone E6H4 ${ }^{\circledR}$, MTM Laboratories AG) for 30 $\min$ at $25^{\circ} \mathrm{C}$. Samples were washed with wash buffer for $5 \mathrm{~min}$, following which visualization reagent was applied and the samples were incubated for $30 \mathrm{~min}$. Subsequently, the sections were washed with wash buffer three times for $5 \mathrm{~min}$. The sections were next incubated in prepared $3,3^{\prime}$-diaminobenzidine solution for $10 \mathrm{~min}$ at $25^{\circ} \mathrm{C}$, which was followed by washing with distilled water. Lastly, the sections were counterstained with Harris hematoxylin for 1 min and dehydrated in three consecutive ethanol baths, followed by three xylene baths. After that, the blades were set up with Entellan resin (Sigma-Aldrich ${ }^{\circledR}$, St. Louis, MO, USA).

Distribution of p16 staining was scored as described by Dijkstra et al. (2010), and representative focal, basal, diffuse, and diffuse full thickness staining are shown in Figure 1. We adapted and regrouped this rating for better evaluation where the negative, focal, and basal staining were considered focal and diffuse and diffuse full thickness staining were considered diffuse.

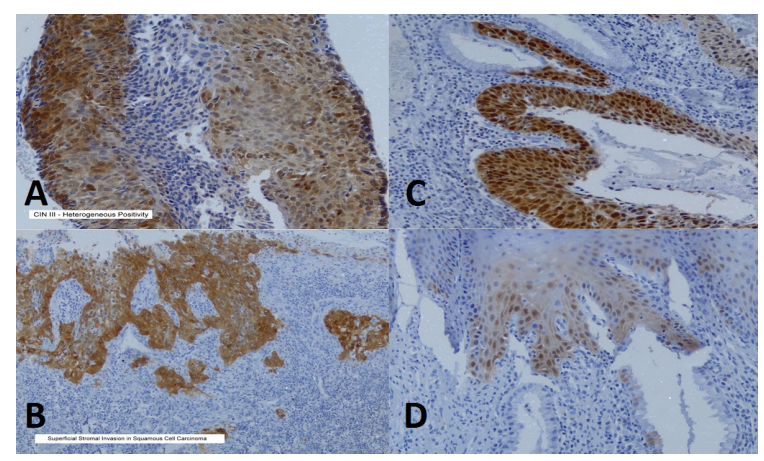

Figure 1. Photomicrograph showing p16 INK4a scoring via immunohistochemistry based on independent nuclear staining. A. Staining showing diffuse immunopositivity in CIN3. B. Cervical tissue with microinvasive SCC showing diffuse p16 INK4a positivity. C. Histological analysis showing high-grade CIN3 with endocervical crypt involvement and strong diffuse immunopositivity. D. Low intense staining in typical squamous metaplasia and focal staining in columnar epithelium (200X magnification).

\section{DNA extraction}

Genomic DNA extraction was performed using the QIAamp ${ }^{\circledR}$ DNA FFPE tissue kit (QIAGEN ${ }^{\circledR}$, Hilden, Germany) on FFPE tissue sections (10- $\mu$ m thick) from CIN3 or invasive uterine cervix squamous cell carcinoma (SCC) biopsies after they were deparaffinized according to manufacturer instructions.

Genetics and Molecular Research 15 (3): gmr.15036840 


\section{DNA amplification}

Extracted DNA was amplified with the INNO-LiPA HPV Genotyping Extra Amp kit (Innogenetics ${ }^{\circledR}$, Ghent, Belgium) that amplifies HPV L1 (late gene 1) sequences via polymerase chain reaction (PCR). SPF $10^{\circledR}$ biotinylated primers amplify 65 base pairs fragments of the L1 open reading frame and 28 oligonucleotide probes recognize 25 different HPV genotypes. The SPF $10^{\circledR}$ PCR system was used with a final reaction volume of $50 \mu \mathrm{L}$ containing $10 \mu \mathrm{L}$ isolated DNA sample and $40 \mu \mathrm{L}$ PCR mixture (biotinylated primers, dNTPs, $\mathrm{MgCl}_{2}, \mathrm{NaN}_{3}$, Taq polymerase and UNG). PCR was conducted according to manufacturer instructions by using the GeneAmp ${ }^{\circledR} 9700$ PCR System Thermal Cycler (Applied Biosystems ${ }^{\circledR}$, Foster City, CA, USA). Cycling conditions included decontamination for $10 \mathrm{~min}$ at $37^{\circ} \mathrm{C}$, denaturation for $9 \mathrm{~min}$ at $94^{\circ} \mathrm{C}$, followed by 40 cycles of $30 \mathrm{~s}$ at $94^{\circ} \mathrm{C}, 45 \mathrm{~s}$ at $52^{\circ} \mathrm{C}$, and $45 \mathrm{~s}$ at $72^{\circ} \mathrm{C}$, with a final extension of $7 \mathrm{~min}$ at $72^{\circ} \mathrm{C}$. Positive and negative controls were provided by the manufacturer.

\section{HPV genotyping}

HPV genotyping was performed with the INNO-LiPA HPV (Innogenetics ${ }^{\circledR}$, Ghent, Belgium) genotyping system, by reverse hybridization. The 28 oligonucleotide probes were tailed with poly (dT) and immobilized as parallel lines to membrane strips. After hybridization and stringent washing, streptavidin-conjugated alkaline phosphatase was added and bound to any biotinylated hybrid formed. Incubation with 5-bromo-4-chloro-3-indolyl-phosphate/ nitro blue tetrazolium (BCIP/NBT) color development substrate produced a purple precipitate that was visually interpreted, using the guide provided (Kleter et al., 1999). Samples were considered valid if they tested positive for a human control gene and either positive or negative for an HPV type-specific gene. Samples that showed no results on the LiPA strip were considered not valid.

\section{Statistical analysis}

For descriptive analysis of the data, the mean, median, and standard deviation were calculated, and the total number of the valid observations to numeric variables was recorded. The proportions of HPV 16 and HPV 52 genotypes were compared to those of the other genotypes, and then parity ( $\leq 4$ versus $>4$ ), p16 classification (focal versus diffused), and infection type (single versus multiple) proportions were compared by using the Binomial (exact) test. Likelihood ratios were used to evaluate the genotypes $(16,52$, or other) versus infection type (single or multiple), and genotype versus p16 classification (focal or diffuse). The Fisher exact test compared the infection type (single or multiple) to p16 classification (focal versus diffuse). All analyses were performed using the SPSS software (v20.0; Chicago, IL, USA). P values less than 0.05 were considered statistically significant.

\section{RESULTS}

Thirteen different HPV genotypes were identified in the indigenous PIX women, and the types of infection (single or multiple), p16 expression, and distribution of p16 staining observed in tissue sections are described in Table 1 . We categorized parity as $\leq 4$ and $>4$ and $32.4 \%$ of the study population had $\leq 4$ childbirths and $67.6 \%$ had $>4$ childbirths $(\mathrm{P}=0.047)$.

Genetics and Molecular Research 15 (3): gmr.15036840 
Ethnicities of the patients were assessed, and the proportions of women with CIN3 or higher were $37.8 \%$ Kayabi, 16.2\%, Kamayurá, 13.5\% Ikpeng, 8.1\% Kalapalo and Suia, 5.4\% Aweti and Juruna, and finally $2.7 \%$ Kuikuro and Mehinako. Histopathological data were analyzed, and it was revealed that there were more patients with CIN3 (64.9\%) than CIN2 (27\%) (Figure 1 ), and few patients presented with microinvasive SCC with clinical staging IA-1.

Table 1. Distribution of indigenous PIX women, the HPV genotypes detected, and p16 protein expression $(\mathrm{N}=37)$.

\begin{tabular}{|c|c|c|c|c|c|c|}
\hline Sample & Age (years) & Parity & Ethnicity & HD & HPV & p16 \\
\hline 1932909 & 39 & 7 & Kayabi & CIN2 & 52 & Diffuse \\
\hline 1965013 & 42 & 9 & Juruna & CIN3 & 16 & Diffuse \\
\hline 2000452 & 29 & 4 & Kuikuro & SCC IA-1 & 16 & Diffuse \\
\hline 2010252 & 56 & 8 & Kalapalo & SCC IA-1 & 52 & Diffuse \\
\hline 2083457 & 65 & 3 & Ikpeng & CIN2 & 11,26 & Focal \\
\hline 2080767 & 24 & 5 & Kayabi & CIN3 & 16 & Focal \\
\hline 2080748 & 44 & 7 & Kamayurá & CIN2 & IA & Diffuse \\
\hline 2080760 & 55 & 6 & Juruna & CIN2 & 52 & ND \\
\hline 2080751 & 39 & 4 & Kamayurá & CIN2 & 52 & Diffuse \\
\hline 2124673 & 68 & 4 & Aweti & CIN2 & 16 & Diffuse \\
\hline 2978894 & 64 & 7 & Kamayurá & CIN3 & 31,33 & Diffuse \\
\hline 2080754 & 33 & 2 & Aweti & CIN3 & $31,33,44$ & Diffuse \\
\hline 2080746 & 40 & 9 & Ikpeng & CIN3 & $\mathrm{N}$ & Diffuse \\
\hline 2080757 & 44 & 9 & Kayabi & CIN3 & 31 & Diffuse \\
\hline 2081613 & 35 & 10 & Suia & CIN3 & IA & Diffuse \\
\hline 1936823 & 29 & 5 & Kayabi & CIN3 & IA & Diffuse \\
\hline 2080763 & 39 & 2 & Suia & CIN3 & 52 & Diffuse \\
\hline 2124691 & 32 & 7 & Kalapalo & CIN3 & 52 & Diffuse \\
\hline 2124692 & 27 & 6 & Kayabi & CIN2 & 52 & Diffuse \\
\hline 2081708 & 34 & 6 & Mehinako & CIN2 & 31 & Diffuse \\
\hline 2124941 & 42 & 9 & Kayabi & CIN2 & 16 & Diffuse \\
\hline 2178263 & 75 & 2 & Kamayurá & CIN2 & $18,44,51$ & Diffuse \\
\hline 2217046 & 27 & 5 & Ikpeng & CIN3 & IA & Diffuse \\
\hline 2228097 & 22 & 5 & Kayabi & CIN3 & 52 & Diffuse \\
\hline 2080773 & 31 & 7 & Kayabi & CIN3 & IA & Diffuse \\
\hline 2784372 & 57 & 6 & Kayabi & CIN3 & 33 & Diffuse \\
\hline 2871989 & 27 & 3 & Ikpeng & CIN3 & 33 & Diffuse \\
\hline 2018499 & 72 & 11 & Kalapalo & CIN2 & 31,44 & Diffuse \\
\hline 2856817 & 65 & 4 & Kayabi & CIN3 & 16,39 & Diffuse \\
\hline 2072341 & 70 & 4 & Kayabi & CIN3 & $31,33,44$ & Diffuse \\
\hline 2124921 & 36 & 6 & Suia & CIN3 & 39,68 & Focal \\
\hline 2080741 & 69 & 1 & Kamayurá & CIN3 & 52 & Diffuse \\
\hline 1977394 & 55 & 10 & Ikpeng & SCC IA-1 & 53 & Diffuse \\
\hline 2871719 & 34 & 7 & Kayabi & CIN2 & 58 & Diffuse \\
\hline 2863218 & 26 & 5 & Kayabi & CIN3 & 31,44 & Diffuse \\
\hline 2871759 & 29 & 4 & Kayabi & CIN3 & 16 & Diffuse \\
\hline 2784364 & 46 & 10 & Kamayurá & CIN3 & 52 & Diffuse \\
\hline Mean & $43.81 \pm 15.89$ & $5.92 \pm 2.58$ & & & & \\
\hline
\end{tabular}

$\mathrm{HD}=$ final histopathological diagnosis; $\mathrm{HPV}=$ genotype; $\mathrm{SCC}=$ microinvasive squamous cell carcinoma; $\mathrm{IA}=$ invalid sample ( $\beta$-globin negative); $\mathrm{N}=$ negative $(\beta$-globin positive/HPV negative); $\mathrm{p} 16=$ color types of $\mathrm{p} 16$; ND $=$ not determined.

We found that there were no statistically significant differences between the proportions of patients with either HPV 16 or HPV 52 compared to the other HPV genotypes between groups and the P values were 0.189 and 0.542 , respectively. The HPV 31 was found in the same proportion as HPV 52 but HPV 31 was always present in multiple infections. The prevalence of single infections was $59.5 \%$, whereas $24.3 \%$ of the study population had multiple infections with up to three different HPV types. The microinvasive SCC were shown 
to have single infections by HPV 16, 52, and 53. When comparing HPV 16, HPV 52, and other HPV type infections with single or multiple infections, statistically significant differences were observed, which are presented in Table 2.

Table 2. Analysis of the infections of the 13 detected HPV genotypes.

\begin{tabular}{|c|c|c|c|}
\hline HPV genotyping & Single infection & Multiple infection & $\mathrm{N}$ \\
\hline 11 & 0 & 1 & 1 \\
\hline 16 & 6 & 1 & 7 \\
\hline 18 & 0 & 1 & 1 \\
\hline 26 & 0 & 1 & 1 \\
\hline 31 & 2 & 5 & 7 \\
\hline 33 & 2 & 3 & 5 \\
\hline 39 & 0 & 2 & 2 \\
\hline 44 & 0 & 5 & 5 \\
\hline 51 & 0 & 1 & 1 \\
\hline 52 & 10 & 0 & 10 \\
\hline 53 & 1 & 0 & 1 \\
\hline 58 & 1 & 0 & 1 \\
\hline 68 & 0 & 1 & 1 \\
\hline Total & 22 & 21 & 43 \\
\hline 16 & $6(85.7)$ & $1(14.3)$ & $7(100)$ \\
\hline 52 & $10(100)$ & $0(0)$ & $10(100)$ \\
\hline Other & $6(23.1)$ & $20(76.9)$ & $26(100)$ \\
\hline Total & 22 & 21 & $43(100)$ \\
\hline
\end{tabular}

Likelihood ratios $\mathrm{P}<0.001$.

Next, p16 expression was assessed via immunohistochemical analysis, and was classified qualitatively as focal or diffuse as described above. One sample was considered invalid, and the results are presented in Table 3.

Table 3. p16 expression in high-grade intraepithelial or invasive lesions.

\begin{tabular}{l|c|c}
\hline p16 expression & $\mathrm{N}$ & $\%$ \\
\hline Focal & 3 & 8.3 \\
\hline Diffuse & 33 & 91.7 \\
\hline Total & 36 & 100 \\
\hline
\end{tabular}

Binomial test $\mathrm{P}<0.001$.

We then compared HPV 16, HPV 52, and other HPV type infections with focal or diffuse $\mathrm{p} 16$ expression, and no significant differences were observed (Table 4). Focal expression of p16 in CIN3 patients was observed in multiple infections by low-risk HPV 11 and high-risk HPV 26. The analysis of single or multiple infections compared to p16 expression (focal or diffuse) revealed that there were no statistically significant differences, but there was a higher prevalence of diffuse expression in all infections $(\mathrm{P}=0.144)$.

Table 4. Classification of p16 protein expression among HPV genotypes.

\begin{tabular}{l|c|c|c}
\hline \multirow{2}{*}{ HPV genotypes } & Focal & \multirow{2}{*}{$\mathrm{N}(\%)$} \\
\cline { 2 - 4 } & $1(14.3)$ & Diffuse & \\
\hline 16 & $0(0)$ & $6(85.7)$ & $7(100)$ \\
\hline 52 & $2(14.3)$ & $9(100)$ & $9(100)$ \\
\hline Other & $3(10)$ & $12(85.7)$ & $14(100)$ \\
\hline Total & & $27(90)$ & $30(100)$ \\
\hline
\end{tabular}

Likelihood ratios $\mathrm{P}=0.320$ 


\section{DISCUSSION}

There are more than 370 million indigenous people living worldwide but most countries do not officially recognize their indigenous groups, and have inaccurate or no published statistical data for these people. Often, indigenous people are over-represented among the poor and disadvantaged, even in developed countries (Gracey and King, 2009).

Cervical cancer mostly occurs in developing countries, where low social-economic status and screening failure makes the disease not identified until it is further advanced (WHO, 2015). In Brazil, regional inequalities in cytological screening bring about the most exposed populations barred from screening (Speck et al, 2009).

Cultural differences in indigenous behavior, like early first intercourse, multiplicity of sexual partners and high parity, increase the risk of cervical cancer development in indigenous women from PIX (Brito et al., 2002; Cunningham et al., 2008; Pereira et al., 2015).

Unfortunately, few studies have been performed in this restricted population, and data have shown that the Papanicolaou test or Pap smear was performed on only $51 \%$ of the women, indicating a need for increased preventive measures (Taborda et al., 2000). Geographic isolation, language differences, and the access to information were the major challenges in this study. Indigenous women with CIN2/3 or more were distributed among the following nine ethnicities: Aweti, Ikpeng, Juruna, Kalapalo, Kamayurá, Kayabi, Kuikuro, Suia, and Mehinako, and were located in 35 hamlets within PIX. The ethnicity with the highest HPV prevalence was Kayabi (37.8\%), which is also the most populous tribe with 386 individuals.

Analysis of HPV types by the use of FFPE cervical tissue has several fields of application with a clinically relevant outcome. Targeted analysis of cervical lesions allows elimination of vaginal infections or transient infections due to recent vaginal activity. INNO-LiPA HPV Genotyping Extra test is based on reverse line blot hybridization and was designed for the identification of 28 different HPV genotypes. As this assay targets the smallest amplicon of any HPV DNA typing system, it is very suitable for the study of FFPE sections, because DNA extracted from FFPE tissue is commonly at a low concentration and fragmented (Bello et al., 2009).

Xue et al. (2015) explained that the prevalence and genotype distribution of HPV infections may be different in each region, but their findings emphasized that HPV genotypes 16,52 , and 58 were the most frequently found genotypes of HR-HPV in Chinese women, which corroborates with our results only to the HPV 16 and 52. Unlike our findings, Smith et al. (2007) noted that HPV 16 appeared to be the most frequent genotype in SCC and HSIL in South/Central America, and HPV 52 was among the less prevalent genotypes. In a recent systematic review, Ciapponi et al. (2011) updated the data on HPV type-specific prevalence in CC and high-grade lesions in Latin America and the Caribbean and demonstrated that the HPV $16(46.5 \%)$ followed by HPV 18 (8.9\%) were the most common HPV genotypes in CIN2/3, while HPV 52 appeared as the sixth more common (4.9\%). These differences between prevalent HPV genotypes are expected but these findings should be used to guide screening follow up protocols, vaccination programs and to monitor changes in HPV typespecific prevalence in this restricted population.

Among the different HPV types that were found herein, we detected two low-risk (11 and 44), two possible HR-HPV (26 and 53), and nine HR-HPV (16, 18, 31, 33, 39, 51, 52, 58, and 68) genotypes. HR-HPV 16 and 52 showed the strongest association with single infection, where the numbers of patients infected with these HPV types was 6 and 10, respectively, whereas no more than 2 patients presented with other HPV types. In contrast, multiple

Genetics and Molecular Research 15 (3): gmr.15036840 
infections were found to be more associated with HPV 31 and 44, noting that HPV 16 was detected in only one multiple infection case and that HPV 52 was detected in none $(\mathrm{P}<0.001)$. In multiple infections, HPV 31 was always accompanied with HPV 33 or 44 and sometimes with both in CIN3. Del Río-Ospina et al. (2015) measured the viral load of HPVs and found that high viral load was most frequently observed in HPV 31 infection in women with low grade lesions or without lesions, similar to what was found in women from Myanmar (Shwe et al., 2015). However, HPV 31 infections are likely transitory and such associations may be mediated by an immune response to high viral loads, which can eliminate the infection; thus, cervical precancerous lesions do not progress further or spontaneously regress (Del RíoOspina et al., 2015).

Multiple infections are frequent in patients with CIN1 and are found in $50 \%$ of these cases (Plummer et al., 2007), while here, we found a greater number of these cases in CIN3 rather than in CIN2. In the present study, the prevalence was single infection with $59.5 \%$ of the cases with HPV 16, 31, 52, 53 and 58, and there was statistically significant difference $(\mathrm{P}=0.029)$ when it was compared to multiple infections associated with other HPV types. Curiously, at least one HR-HPV was present in all cases of multiple infections. Pitta et al. (2009) observed that in a Brazilian population, multiple infections reached a prevalence of $64.7 \%$ with a strong association with HPV 16 and 58, followed by an association with HPV 16 and 52, which is contradictory to the results of the present study. In the updated meta-analysis of Ciapponi et al. (2011), it was found a prevalence of $16.8 \%$ multiple infections in high-grade lesions in Latin America and the Caribbean, with cases mainly from Brazil, whilst in the present study we found $24.3 \%$ of multiple infections.

Trottier et al. (2006) demonstrated that there was an increase in risk of CIN and CC in patients with multiple infections by HPV. Furthermore, a study performed by van der Graaf's group in 2002, provided evidence that multiple HPV infections act synergistically in cervical carcinogenesis, and it was also associated with poor response and with reduced survival in cervical cancer patients (van der Graaf et al., 2002; Munagala et al., 2009).

Researchers have been seeking a diagnostic separation of low-grade lesions from those with a high potential of progression to malignancy by means of molecular markers and traditional morphological methods, which may increase predictive value, sensitivity, and diagnostic specificity (Focchi et al., 2007). Nevertheless, due to the variation in immunohistochemistry assays and microscopic interpretation criteria, many studies have demonstrated a relationship between p16 overexpression and CIN3 (Tsoumpou et al., 2009). In the present study, p16 overexpression was significantly associated with the diffuse group rather than the focal group $(\mathrm{P}<0.001)$, demonstrating a high sensitivity and specificity to diagnosis cervical premalignant lesions (Dijkstra et al., 2010). The HPV genotype (16 and 52 versus others) did not show a statistically significant correlation with p16 expression (P $=0.320$ ), and independent of genotype, p16 expression was highlighted in the diffuse group. This observation may be explained by action of the oncoprotein E7 from HR-HPV over RB, independently of genotype, leading RB inactivation, overexpression of p16, lack of cell cycle control and starting the tumor progress (Schiffman et al., 2007; Hamid et al., 2009; Peurala et al., 2013). Tsoumpou et al. (2009) performed a meta-analysis to evaluate p16 expression in cervix samples and found that it ranged from $2 \%$ in normal biopsies, $38 \%$ in CIN1 with marked diffuse staining for p16, to $68 \%$ in CIN2 and $82 \%$ in CIN3, in agreement with our current data. In three cases, focal p16 expression was observed but low-risk HPV or HR-HPV (11 and 26) was possibly detected only in one.

Genetics and Molecular Research 15 (3): gmr.15036840 
Infection types (single or multiple) were then compared to p16 expression, and in multiple infections, $22.2 \%$ were considered focal and $77.8 \%$ were considered diffuse, whereas $95.2 \%$ of single infection cases were diffuse, though the difference was not significant $(\mathrm{P}=0.144)$.

Indigenous women from PIX presented with high rates of HPV 52 in CIN3, while other HPV types were uncommon in the population. p16 expression was not influenced by HPV genotype, and exhibited a high sensitivity and specificity to intraepithelial lesions and HPV-induced carcinoma.

Cunningham et al. (2008) highlighted that indigenous people are less likely to develop certain types of cancer, but are more likely to have poor prognoses due to cultural and geographical obstacles. Speck et al. (2009) analyzed native PIX women and found that they were increasingly being exposed to certain diseases as a consequence of their increased presence in urban centers and the presence of non-native people in some indigenous hamlets. This epidemiological panorama allows for HPV control in some isolated groups, and for monitoring the population profile. The lack of healthcare in indigenous populations is an exacerbating factor. It is essential to encourage these people to take responsibility for their healthcare programs (Gracey and King, 2009). Furthermore, it is important to point out that a nonavalent vaccine containing HPV $6,11,16,18,31,33,45,52$, and 58 antigens may be an effective prevention method for children of both sexes starting at the age of 9 years as this vaccine was licensed by the US Food and Drug Administration in 2014 (Herrero et al., 2015). For example, the incidence of mortality in indigenous peoples from cervical cancer in Australia decreased largely due to the action of preventive programs (Cunningham et al., 2008).

In conclusion, p16 immunoexpression was diffuse in $91.7 \%$ of patients with CIN3 or higher, and it appeared that there were no modifications in its expression due to the HPV genotype or amount of viruses in the infection. Nonetheless, more studies are necessary to further our understanding of this restricted group. The indigenous women from Xingu Park have suffered from societal influences such as from the introduction of viruses. In the current study, $13 \mathrm{HPV}$ genotypes were detected in the high-grade cervical intraepithelial lesions from this population including a high prevalence of HPV 52 and 16, which can be detrimental to this important Brazilian ethnic group.

\section{Conflicts of interest}

The authors declare no conflict of interest.

\section{ACKNOWLEDGMENTS}

Research supported by Coordenação de Aperfeiçoamento de Pessoal de Nível Superior (CAPES) grant.

\section{REFERENCES}

Bell MC, Schmidt-Grimminger D, Patrick S, Ryschon T, et al. (2007). There is a high prevalence of human papillomavirus infection in American Indian women of the Northern Plains. Gynecol. Oncol. 107: 236-241. http://dx.doi. org/10.1016/j.ygyno.2007.06.007

Bello BD, Spinillo A, Alberizzi P, Cesari S, et al. (2009). Validation of the $\mathrm{SPF}_{10}$ LiPA human papillomavirus assay using formalin-fixed paraffin-embedded cervical biopsy samples. J. Clin. Microbiol. 47: 2175-2180.

Bergeron C, Ordi J, Schmidt D, Trunk M, et al. (2010). Conjunctive p16INK4a testing significantly increases accuracy in diagnosing high-grade cervical intraepithelial neoplasia. Am. J. Clin. Pathol, 133: 395-406.

Genetics and Molecular Research 15 (3): gmr.15036840 
Brito EB, Martins SJ and Menezes RC (2002). Human papillomaviruses in Amerindian women from Brazilian Amazonia. Epidemiol. Infect. 128: 485-489. http://dx.doi.org/10.1017/S0950268802006908

Ciapponi A, Bardach A, Glujovsky D, Gibbons L, et al. (2011). Type-specific HPV prevalence in cervical cancer and highgrade lesions in Latin America and the Caribbean: systematic review and meta-analysis. PLoS One 6: e25493. http:// dx.doi.org/10.1371/journal.pone.0025493

Cunningham J, Rumbold AR, Zhang X and Condon JR (2008). Incidence, aetiology, and outcomes of cancer in Indigenous peoples in Australia. Lancet Oncol. 9: 585-595. http://dx.doi.org/10.1016/S1470-2045(08)70150-5

Darragh TM, Colgan TJ, Thomas Cox J, Heller DS, et al. (2013). The Lower Anogenital Squamous Terminology Standardization Project for HPV-associated lesions: background and consensus recommendations from the College of American Pathologists and the American Society for Colposcopy and Cervical Pathology. Int. J. Gynecol. Pathol. 32: $76-115$.

Del Río-Ospina L, Soto-De León SC, Camargo M, Moreno-Pérez DA, et al. (2015). The DNA load of six high-risk human papillomavirus types and its association with cervical lesions. BMC Cancer 15: 100. http://dx.doi.org/10.1186/ $\underline{\text { s12885-015-1126-Z }}$

Dijkstra MG, Heideman DAM, de Roy SC, Rozendaal L, et al. (2010). p16(INK4a) immunostaining as an alternative to histology review for reliable grading of cervical intraepithelial lesions. J. Clin. Pathol. 63: 972-977. http://dx.doi. org/10.1136/jcp.2010.078634

Focchi GRA, Silva IDCG, Nogueira-de-Souza NC, Dobo C, et al. (2007). Immunohistochemical expression of p16(INK4A) in normal uterine cervix, nonneoplastic epithelial lesions, and low-grade squamous intraepithelial lesions. J. Low. Genit. Tract Dis. 11: 98-104.http://dx.doi.org/10.1097/01.lgt.0000245042.29847.dd

Gracey M and King M (2009). Indigenous health part 1: determinants and disease patterns. Lancet 374: 65-75. http:// dx.doi.org/10.1016/S0140-6736(09)60914-4

Hamid NA, Brown C and Gaston K (2009). The regulation of cell proliferation by the papillomavirus early proteins. Cell. Mol. Life Sci. 66: 1700-1717. http://dx.doi.org/10.1007/s00018-009-8631-7

Herrero R, González P and Markowitz LE (2015). Present status of human papillomavirus vaccine development and implementation. Lancet Oncol. 16: e206-e216. http://dx.doi.org/10.1016/S1470-2045(14)70481-4

Kahn M, Campanili M, Gauditano B, Villas-Bôas A, et al. (2011). Instituto Socioambiental: Almanaque Socioambiental Parque Indígena do Xingu 50 anos, Chemistry \& Biodiversity, Vol. 1, São Paulo.

Kietpeerakool C, Kleebkaow P and Srisomboon J (2015). Human papillomavirus genotype distribution among thai women with high-grade cervical intraepithelial lesions and invasive cervical cancer: a literature review. Asian Pac. J. Cancer Prev. 16: 5153-5158.

Klaes R, Benner A, Friedrich T, Ridder R, et al. (2002). p16INK4a immunohistochemistry improves interobserver agrément inthe diagnosis of cervical intraepithelial neoplasia. Am. J. Surg. Pathol. 26: 1389-1399.

Kleter B, Van Doorn LJ, Schrauwen L, Molijn A, et al. (1999). Development and clinical evaluation of a highly sensitive PCR-reverse hybridization line probe assay for detection and identification of anogenital human papillomavirus. $J$. Clin. Microbiol. 37: 2508-2517.

Li N, Franceschi S, Howell-Jones R, Snijders PJ, et al. (2011). Human papillomavirus type distribution in 30,848 invasive cervical cancers worldwide: Variation by geographical region, histological type and year of publication. Int. J. Cancer 128: 927-935. http://dx.doi.org/10.1002/ijc.25396

Munagala R, Donà MG, Rai SN, Jenson AB, et al. (2009). Significance of multiple HPV infection in cervical cancer patients and its impact on treatment response. Int. J. Oncol. 34: 263-271.

Okada S, Harano T, Myo Khin, Harano T, et al.; Mu Mu Shwe; Kyi Kyi Nyunt; Hlaing Myat Thu; Hla Myat Mo Mo; Mo Mo Win; Khin Khin Oo; Khin Thet Wai; Khin Saw Aye (2015). Trend of human papillomavirus genotypes in cervical neoplasia observed in a newly developing township in Yangon, Myanmar. Acta Med. Okayama 69: 51-58.

Pereira ER, Speck NM, Rodrigues DA, De Freitas VG, et al. (2015). Prevention, diagnosis and treatment of cervical cancer precursor lesions at the Xingu Indigenous Park, Brazil. Eur. J. Gynaecol. Oncol. 36: 376-382.

Peurala E, Koivunen P, Haapasaari KM, Bloigu R, et al. (2013). The prognostic significance and value of cyclin D1, CDK4 and p16 in human breast cancer. Breast Cancer Res. 15: R5.http://dx.doi.org/10.1186/bcr3376

Pitta DR, Sarian LO, Campos EA, Rabelo-Santos SH, et al. (2009). Phylogenetic classification of human papillomavirus genotypes in high-grade cervical intraepithelial neoplasia in women from a densely populated Brazilian urban region. Sao Paulo Med. J. 127: 122-127. http://dx.doi.org/10.1590/S1516-31802009000300003

Plummer M, Schiffman M, Castle PE, Maucort-Boulch D, et al.; ALTS Group (2007). A 2-year prospective study of human papillomavirus persistence among women with a cytological diagnosis of atypical squamous cells of undetermined significance or low-grade squamous intraepithelial lesion. J. Infect. Dis. 195: 1582-1589. http://dx.doi. org $/ 10.1086 / 516784$

Genetics and Molecular Research 15 (3): gmr.15036840 
Schiffman M, Castle PE, Jeronimo J, Rodriguez AC, et al. (2007). Human papillomavirus and cervical cancer. Lancet 370 : 890-907. http://dx.doi.org/10.1016/S0140-6736(07)61416-0

Shwe MM, Nyunt KK, Okada S, Harano T, et al. (2015). Trend of human papillomavirus genotypes in cervical neoplasia observed in a newly developing township in Yangon, Myanmar. Acta Med. Okayama 69: 51-58.

Smith JS, Lindsay L, Hoots B, Keys J, et al. (2007). Human papillomavirus type distribution in invasive cervical cancer and high-grade cervical lesions: a meta-analysis update. Int. J. Cancer 121: 621-632. http://dx.doi.org/10.1002/ijc.22527

Speck NM, Pereira ER, Schaper M, Tso FK, et al. (2009). Uterine cervical neoplasia prevention in Parque Indigena do Xingu. Eur. J. Gynaecol. Oncol. 30: 415-417.

Taborda WC, Ferreira SC, Rodrigues D, Stávale JN, et al. (2000). Rastreamento do câncer de colo uterino em índias do Parque Indígena do Xingu, Brasil central. Rev. Panam. Salud Publica 7: 92-96. http://dx.doi.org/10.1590/S102049892000000200004

Tonon SA, Picconi MA, Zinovich JB, Nardari W, et al. (2004). Human papillomavirus cervical infection in Guarani Indians from the rainforest of Misiones, Argentina. Int. J. Infect. Dis. 8: 13-19. http://dx.doi.org/10.1016/j.ijid.2003.03.001

Torres M, Fraile L, Echevarria JM, Hernandez Novoa B, et al. (2012). Human papillomavirus (HPV) genotyping: automation and application in routine laboratory testing. Open Virol. J. 6: 144-150.

Trottier H, Mahmud S, Costa MC, Sobrinho JP, et al. (2006). Human papillomavirus infections with multiple types and risk of cervical neoplasia. Cancer Epidemiol. Biomarkers Prev. 15: 1274-1280. http://dx.doi.org/10.1158/1055-9965. EPI-06-0129

Tsoumpou I, Arbyn M, Kyrgiou M, Wentzensen N, et al. (2009). p16(INK4a) immunostaining in cytological and histological specimens from the uterine cervix: a systematic review and meta-analysis. Cancer Treat. Rev. 35: 210220. http://dx.doi.org/10.1016/j.ctrv.2008.10.005

van der Graaf Y, Molijn A, Doornewaard H, Quint W, et al. (2002). Human papillomavirus and the long-term risk of cervical neoplasia. Am. J. Epidemiol. 156: 158-164.

Xue H, Lin X, Li T, Yan X, et al. (2015). Prevalence and genotype distribution of human papillomavirus infection in asymptomatic women in Liaoning province, China. J. Med. Virol. 87: 1248-1253. http://dx.doi.org/10.1002/ imv.24029

World Health Organization (2015). Human papillomavirus (HPV) and cervical cancer. Fact sheet $\mathrm{N}^{\circ} 380$. http://www.who. int/mediacentre/factsheets/fs380/en/.

Zhang G, Yang B and Abdul-Karim FW (2105). p16 immunohistochemistry is useful in confirming high-grade squamous intraepithelial lesions (HSIL) in women with negative HPV testing. Int. J. Gynecol. Pathol. 34: 180-186.

Genetics and Molecular Research 15 (3): gmr.15036840 